\section{Andamios Revista de Investipación Social}

Andamios. Revista de Investigación Social ISSN: 1870-0063

revistaandamios@uacm.edu.mx

Universidad Autónoma de la Ciudad de México México

Bacarlett Pérez, María Luisa; Pérez Bernal, Ángeles Ma. del Rosario

La comunidad aporética: tensiones entre la política y lo político

Andamios. Revista de Investigación Social, vol. 11, núm. 24, enero-abril, 2014, pp. 35-58

Universidad Autónoma de la Ciudad de México

Distrito Federal, México

Disponible en: http://www.redalyc.org/articulo.oa?id=62832750003

- Cómo citar el artículo

Número completo

- Más información del artículo

- Página de la revista en redalyc.org

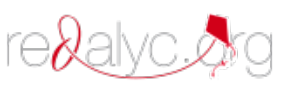

Sistema de Información Científica

Red de Revistas Científicas de América Latina, el Caribe, España y Portugal

Proyecto académico sin fines de lucro, desarrollado bajo la iniciativa de acceso abierto 


\title{
LA COMUNIDAD APORÉTICA: TENSIONES ENTRE LA POLÍTICA Y LO POLÍTICO
}

\author{
María Luisa Bacarlett Pérez \\ Ángeles Ma. del Rosario Pérez Bernal ${ }^{* *}$
}

\begin{abstract}
Resumen: Se analiza el estatus de la comunidad a partir de una perspectiva posfundacional, misma que permite repensar la relación entre lo político y la política, así como cuestionar la necesidad de un fundamento fuerte que sustente la vida política concreta, pero también la perspectiva de rechazar todo fundamento. Partiendo de algunas ideas heideggerianas en las que el ser ya no es concebido como fundamento, sino como acontecimiento, se trata de replantear aquél como algo que sólo puede fundar en tanto se oculta o vacila; ello puede permitir repensar la comunidad en términos no esencialistas, es decir, concibiéndola como una realidad aporética que sólo puede realizarse en la medida en que no se realiza.

Palabras clave: Comunidad, paradoja, lo político, la política, posfundacionalismo
\end{abstract}

... el Mal es, bajo condición de una verdad, querer a cualquier precio forzar la denominación de lo innombrable.

Alain Badiou. La ética

\footnotetext{
* Profesora-investigadora de tiempo completo de la facultad de Humanidades de la Universidad Autónoma del Estado de México, doctora en filosofía por la Universidad Autónoma Metropolitana. Correo electrónico: bacarlett@gmail.com.

** Profesora-investigadora de tiempo completo de la Facultad de Humanidades de la Universidad Autónoma del Estado de México, doctora en letras por la UNAM. Correo electrónico: rosariopbernal@gmail.com.
} 


\section{REPENSAR LA COMUNIDAD}

Si hay un rasgo que conjunta los diferentes gestos en torno a la comunidad en algunos autores de cuño contemporáneo, que algunos han coincidido en llamar "posfundacionales", es sin duda la insistencia en concebir a la comunidad en términos aporéticos. Entre ellos encontramos a JeanLuc Nancy, Alain Badiou, Roberto Esposito, Peter Sloterdijk, Ernesto Laclau y Giorgio Agamben, principalmente. Las coincidencias de pensamiento entre estos autores no pueden extenderse a la totalidad de sus obras; sin embargo, el punto en el cual muestran una evidente cercanía es precisamente en el que se refiere al tema de la comunidad.

Muchas de las ideas de estos autores parten de la crisis del ideal comunista de una sociedad igualitaria, sin clases, de aquello que pareció desvanecerse con la caída del muro de Berlín y del comunismo real. Sabemos que tal crisis fue analizada desde los puntos de vista más variados; sin embargo, uno de los más conocidos fue la tesis del "fin de la historia" que abanderaron pensadores como Francis Fukuyama. Desde la perspectiva de Fukuyama, el fin de la historia está íntimamente ligado al fin de las ideologías - y por ende, al dominio absoluto de la economía-, al fin del enfrentamiento entre dos visiones del mundo que se tradujo en la hegemonía del capitalismo a nivel planetario. Se esperaba entonces que con la caída del socialismo, el fin de la lucha de clases y el triunfo de una sola perspectiva político-económica a nivel mundial — la democracia liberal — por fin se arribaría a un estado de cosas más o menos plano en el que ahora sí podría aspirarse a conformar una verdadera comunidad, si por ella podía entenderse un estar en común carente de conflictos fundamentales, donde lo primordial no sería lograr el reconocimiento, sino deslizarse sobre la promesa de igualdad que el mercado, con sus altibajos, parecía prometer. El liberalismo económico se presentaba, así, como la llave que permitía satisfacer los deseos materiales de los hombres y, con ello, su deseo de reconocimiento. Sin embargo, el propio Fukuyama cae en cuenta de que por debajo de estos buenos deseos, el liberalismo cultiva secretamente en cada uno de nosotros una forma de megalothymia que lleva a los individuos no solamente a querer ser reconocidos como iguales a los otros (isothymia), sino como superiores. En suma, Fukuyama también 
deja ver la sospecha de que el liberalismo ha quedado muy lejos de subsanar esa comunidad ideal que ni siquiera el propio comunismo pudo sostener. Según el polémico intelectual estadounidense, aunque teóricamente la democracia liberal tendría que habernos convertido...

[...] en miembros indiferenciados de un Estado universal y homogéneo, cada uno similar a los demás donde quiera que se vaya en el planeta. [Al final, lo que queremos es] ser ciudadanos más bien burgueses, [pues] en fin de cuentas [encontraríamos] aburrida la vida de una esclavitud sin señores — la vida del consumo racional-. [...] Esta es la 'contradicción' que la democracia liberal no ha resuelto.

A largo plazo, la democracia liberal puede verse subvertida internamente ya sea por un exceso de megalothymia, ya por un exceso de isothymia, o sea, por el deseo fanático de un reconocimiento igual. Mi intuición es que la mayor amenaza para la democracia vendrá de la primera (Fukuyama, 1992: 419).

La democracia liberal no pudo construir, al final de cuentas, ni una sociedad más justa ni más igualitaria, es decir, estuvo muy lejos de construir una verdadera comunidad. Pero el comunismo no hizo mejor las cosas, tal y como lo expone Maurice Blanchot, tendríamos que reconocer que su apuesta no fue exactamente dar lugar a una sociedad perfecta, sino más bien a una sociedad transparente en la que la promesa de igualdad se basaba en un ideal de inmanencia: si cada uno es dueño de su fuerza de trabajo y si se supera la explotación y enajenación a la que se ha sido sometido, entonces cada hombre puede asumirse como producto de sí mismo, como su obra. Lo cual no deja de ser paradójico, pues ello acerca de manera extrema el comunismo al individualismo, es decir, a una postura en la que cada quien es su obra y, por ende, irreductible a los demás; con lo cual la reciprocidad que implicaba el ideal comunista de comunidad se diluye hasta desaparecer.

Esta reciprocidad del comunismo y del individualismo, denunciado por los defensores más austeros de la reflexión 
contra-revolucionaria (de Maistre, etcétera), y también por Marx, nos conduce a poner en causa la noción misma de reciprocidad. Pero si la relación del hombre con el hombre cesa de ser la relación del Mismo con el Mismo e introduce al otro como irreductible y, en su igualdad, siempre en disimetría en relación a aquél que lo considera, entonces es otra forma de relación la que se impone y que impone otra forma de sociedad que uno apenas osaría nombrar 'comunidad'. O tendríamos que aceptar llamarla así preguntándonos qué está en juego en el pensamiento de una comunidad y si ésta, existiera o no, no nos plantea al final la ausencia de comunidad (Blanchot, 1983: 12).

Tal y como lo expone Blanchot, el ideal comunista de comunidad no hizo más que profundizar la enorme distancia entre individuo y comunidad, dejando al primero como amo y señor de la situación. Pero la apuesta liberal no fue mejor, nos dejó encerrados en un individualismo más acendrado donde la necesidad de ser reconocido como igual se transformó en la sed de ser identificado como superior. En suma, ni comunismo ni liberalismo resolvieron el problema del estar en común: ambos terminaron reforzando la figura de un individuo irreductible que, o bien es obra absoluta de su hacer, o bien lleva al extremo una cierta megalomanía en la cual los otros terminan, si no ausentes, al menos súbditos de la propia grandeza. Frente a este panorama que resulta poco esperanzador, la pregunta que queda en el aire es saber si algo como la comunidad es aún posible o realizable. Las dos respuestas más fáciles e inmediatas fueron éstas: o bien renunciábamos sin más al afán de hacer comunidad, de construir una comunidad como espacio de identidad, igualdad y reconocimiento mutuo; o bien se replanteaban los términos y los fracasos — tanto comunistas como liberales- y se buscaba reformular la cuestión en otros términos, quizá con menos exigencias, con menos idealismo o, como lo expresa Roberto Esposito, renunciando a nuestra idea "mítica" de comunidad. Para Esposito una de las razones del fracaso del afán occidental por hacer comunidad es que nuestra idea de la misma es mítica, poco realista: "El mito de una comunidad transparente a sí misma en la que cada cual comunica 
al otro su éxtasis comunitario. El sueño de absoluta inmanencia. Sin ninguna mediación, filtro o signo que interrumpa la fusión recíproca de las conciencias. Sin ninguna distancia, discontinuidad, diferencia con otro [...]" (Esposito, 2009: 31).

La gran debilidad de los proyectos occidentales por construir la comunidad perfecta versó en que se veía a ésta como la clave de superación de toda diferencia, como artilugio de fusión total en la cual las distancias y las desigualdades se verían superadas por la imagen de la absoluta identidad; en suma, la comunidad como la superación de todo conflicto y divergencia: homogeneidad y planicie total. Es de esperar que una demanda tan alta fuera difícil de cumplir, de ahí que ciertos pensadores, muchos de ellos influenciados por Heidegger, y que dieron lugar a una cierta forma de "heideggerianismo de izquierda", buscaron pensar la comunidad asumiendo precisamente su carácter constitutivamente finito, incompleto. Pero asumir este doble carácter finito e incompleto significaba, ante todo, repensar a la comunidad no buscando una esencia sustantiva y estable que la definiera, sino buscando precisamente lo contrario: verla como un proceso interminable lleno de paradojas e insuficiencias.

Lo que estos teóricos intentaban era dar una concepción del estar en común pero renunciando a todo fundamento y a toda esencia estable, de ahí que se les haya caracterizado como pensadores "posfundacionales". Sin embargo, tal postura no implicaba renunciar a todo fundamento, antes bien, se trataba de repensar a éste como algo que funda sólo en la medida en que se retira, en que renuncia a ser fundamento. Para ellos, la cuestión no es "[...] apuntar a una esencia constitutiva y estable, sino, más bien, a un proceso interminable. En consecuencia, el a-bismo o ausencia de fundamento 'se hace presente' en el fundamento bajo la forma de un inacabable sacaecimiento [...]" (Marchart, 2009: 37). Lo que aquí nos interesa subrayar es que desde una perspectiva posfundacional, repensar la comunidad demandaba renunciar a pensarla en términos sustanciales o esencialistas, por ende, volver a pensarla pero a partir de su carácter finito e inacabado, renunciando a todo fundamento permanente: se necesitaba repensarla como paradoja.

En su raíz etimológica, la palabra paradoja nos remite a "lo contrario a la opinión" y, como ya se daba cuenta de ella desde la antigüedad 
- por ejemplo, con Cicerón-, se refiere a las cosas que nos maravillan: "En efecto, la paradoja maravilla, porque propone que algo que parece asombroso pueda ser tal como se dice que es. En general, puede decirse que toda proposición filosófica o científica que no haya pasado al acervo común ofrece un perfil paradójico" (Villarmea, 2011: 11). Tomando en cuenta lo anterior, partimos de la idea de que una paradoja no solamente da cuenta de un error del pensamiento, de una aporía que no nos deja pensar correctamente, antes bien, puede producir el efecto contrario, puede darnos qué pensar, puede abrirnos rutas distintas de pensamiento frente a los caminos claros y bien conocidos; podemos, así, considerarlas en gran medida como "los átomos de la filosofía, puesto que son los puntos de partida básicos de la especulación sistemática" (Sorensen, 2007: 13). Por tal razón tienen un evidente interés filosófico, ya que no sólo nos indican cuándo estamos pensando incorrectamente, sino también nos invitan a revisitar nuestros razonamientos, definiciones y explicaciones.

La propuesta central del pensamiento posfundacional asume que al tratar de definir la comunidad como una entidad clara, separada y absoluta, es inevitable caer en ciertos contrasentidos que terminan cuestionando tales atributos. Para estos autores, pensar la comunidad en toda su complejidad significa hacerse cargo de los contrasentidos y aporías que aparecen siempre que queremos concebirla como una entidad unívoca, separada y completa. En gran medida, el contrasentido que encuentran a la hora de reflexionar sobre el estar en común se parece mucho a la paradoja lógica que Russell encontró en la teoría de conjuntos y que, a grandes rasgos, muestra que la clase de todas las clases que no son miembros de sí mismas implica una contradicción, a saber, que si es miembro de sí misma, entonces no es miembro de sí misma, y viceversa, que si no es miembro de sí misma, entonces es miembro de sí misma. La manera posfundacional de concebir la comunidad está en gran consonancia con la paradoja antes expuesta, con lo cual la comunidad sería y no sería a la vez elemento de sí misma. Para ser más claros, se trata de un contrasentido que se traduciría en que la comunidad sólo es realizable en la medida en que no es realizable, pero este contrasentido lejos de hacer añicos nuestra idea y la posibilidad misma de la comunidad es precisamente lo que la haría factible. 
La perspectiva posfundacional en torno a la comunidad nos permite repensarla en términos no sustanciales ni esencialistas, es decir, sin apelar a un fundamento último que la defina, a la vez que nos permite concebirla en términos paradójicos, como algo que sólo puede realizarse en tanto no se realiza: a la vez miembro y no miembro de sí misma. Con todo, no deja de ser curioso que los autores que se han acercado de esta manera al problema de la comunidad lo han hecho no desde la esfera de la política, sino a partir de lo político, es decir, desde una perspectiva filosófico-ontológica de la que podría esperarse un lenguaje y una serie de argumentos más bien fundamentalistas o esencialistas; sin embargo, nos encontramos con lo contrario: son autores que tratando de asumir el carácter incompleto y finito de la comunidad se acercan a la ontología, pues encuentran en ésta — sobre todo a partir de ciertos conceptos heideggerianos- los argumentos necesarios para encontrar un nuevo fundamento de aquélla, fondo que en realidad es ausencia de todo fundamento. "Lo que está en juego en el pensamiento posfundacional es el estatus atribuido a los fundamentos, según el cual la ausencia primordial (u ontológica) de un fundamento último es, en sí misma, la condición de posibilidad de los fundamentos en cuanto presentes, vale decir, en su objetividad o 'existencia' empírica como seres ónticos" (Marchart, 2009: 30).

Bien podríamos decir que lo que está en juego en el pensamiento posfundacional, una de las raíces constitutivas de tal forma de pensamiento, es la llamada diferencia ontológica o diferencia entre lo político y la política, tema que tiene sus raíces tanto en ciertas ideas heideggerianas como en la obra de Carl Schmitt, Hanna Arendt y Paul Ricoeur; sin embargo, en este trabajo nos concentraremos en el primero.

\section{HEIDEGGER Y EL FUNDAMENTO DESFONDADO}

Tratar de definir la diferencia entre la política y lo político implica un movimiento triple, pues no sólo se trata de definir ambos conceptos sino, sobre todo, reclama dejar claro el lugar de la diferencia, que en este caso se torna mucho más importante que los términos mismos que estamos tratando de distinguir. A ello habría que agregar que 
esta idea, de firmes raíces heideggerianas, también se encuentra problematizada en otros filósofos que difícilmente podríamos abarcar en este trabajo. Nos conformaremos entonces con dar cuenta, aunque someramente, de la forma que toma esta idea en Heidegger, sobre todo en textos como Aportes a la filosofía e Historia del ser.

El caso de Heidegger es interesante, sabemos del frecuente error de algunas — quizá muchas_ lecturas que sin más hipostasian o quieren hacer del Ser (Sein) heideggeriano un fundamento ontológicamente fuerte. Quizá esta es una de las razones por las que el propio Heidegger se ve obligado, sobre todo después de 1930, a dar un cierto giro a su propuesta filosófica y con ello dar lugar a otra forma de pensar la metafísica, una en la que se busca ya no tanto pensar al ser como fundamento, sino como acontecimiento. Es en particular en obras como Aportes a la filosofía. Acerca del acontecimiento y La historia del ser ${ }^{1}$ donde Heidegger realiza una giro importante en relación con la diferencia entre lo óntico y lo ontológico. Tradicionalmente la metafísica ha buscado fundamentar lo óntico - esta realidad fáctica hecha de entes concretos, de cosas variadas, lo propiamente mundano- en un sustrato mucho más fundamental que es el ámbito del ser, de algo que es la condición de posibilidad de cada cosa y cada ente, de nosotros mismos, pero que no es ninguno de estos en particular: el ser se dice de muchas maneras, o como lo diría más puntualmente Aristóteles, "[... 'lo que es', sin más precisiones, se dice en muchos sentido" (Met, 1026b). El afán de la metafísica ha sido entonces, tradicionalmente, dar cuenta del mundo fenoménico, intentando encontrar ese fondo esencial o sustancial que le da su existencia y consistencia. Sin embargo, para Heidegger el error de la metafísica ha sido que ésta, al preguntarse por el ser, sólo ha alcanzado a fijarse en los entes, a confundir al ser en los entes. "Mientras el 'ser [Seyn]' sea concebido como entidad, como lo de alguna manera "general" y con ello como una conmutada condición del ente detrás del ente, es decir, de su representatividad, es decir, de su objetividad, y, finalmente, de su ser-'en sí', el ser [Seyn] mismo es rebajado a la verdad del ente, a la corrección del re-presentar" (Heidegger, 2011a: 88).

\footnotetext{
${ }^{1}$ Aportes a la filosofía. Acerca del acontecimiento apareció por vez primera en alemán en 1989, pero fue escrito entre 1936 y 1938; La historia del ser fue escrito entre 1939 y 1940, y publicado en alemán hasta 1998.
} 
Sin embargo, el giro ocurrido a partir de los Aportes a la filosofía nos introduce en una manera distinta de entender la metafísica, como ya hemos apuntado, una en la que lo importante no es concebir al ser en términos de fundamento sino de acontecimiento. Esto no significa que Heidegger renuncie a todo fundamento ontológico; sin embargo, ahora el fundamento es algo que sólo se devela en su retirada, en su ausencia. Esta es una idea difícil de comprender porque representa, sin duda, una paradoja, una forma aporética en la cual el fundamento sólo puede cumplir su tarea de fundamentar en la medida en que se retira, en que no se encuentra completo ni presente en cosa o ente alguno. No significa, sin embargo, la pura cancelación del fundamento, su pura ausencia, tampoco significa presencia sin más, sino la paradójica forma de un fundamento desfondado.

Para Heidegger, la ausencia de fundamento es propia de la naturaleza de un abismo, vale decir, de un fundamento sin fundamento, de un fundamento sin fondo. De ese modo, la fundación todavía acontece: la 'función' de fundamento no desaparece por completo. No obstante, acontece en la medida en que pasa a través de un 'a-bismo' (Marchart, 2009: 34).

El fundamento del que habla Heidegger no refiere a algo ni completamente lleno ni completamente vacío, tendríamos que hablar más bien de algo no-llenado, no-cumplido, algo que al estar no-lleno permanece abierto, es decir, implica una extraordinaria apertura en la que el acontecimiento aún es posible. De ahí que el ser no pueda ya ser visito como fundamento último y tampoco la realidad fáctica como mero simulacro de esa profundidad ontológica originaria; antes bien, el ser, en cuanto no-lleno, permanece abierto a tomar esta u otra forma de lo fáctico, de lo mundano, con lo cual, sin que desaparezca la brecha existente entre ambos, entre los dos se origina un umbral de indiferenciación, un quiasmo, donde lo óntico y lo ontológico se contienen mutuamente, en una especie de superposición cruzada. 
Heidegger pone el acento en el hecho de que las dos dimensiones tienen que diferenciarse de alguna manera, pero, al mismo tiempo, no pueden diferenciarse con claridad, pues se cruzan incesantemente una con otra. Debido a ese entrecruzamiento inseparable del fundamento con el abismo, el fundamento puede ser reconocido como abismo y, sin embargo, conservar algo de su propia naturaleza en tanto fundamento. Lo que la figura del quiasmo le permite a Heidegger es expresar la intrincada relación o reversibilidad de ambos términos y, a la vez, su no identidad (Marchart, 2009: 35).

El quiasmo es, en este sentido, una verdadera zona de indiferenciación entre lo óntico y lo ontológico que, con todo, no los vuelve idénticos, pero tampoco entabla entre ellos una distancia irreconciliable. Así, el fundamento está ahí pero no a la manera de la total presencia, tampoco está absolutamente ausente, más bien se encuentra en la forma de la dubitación, de la hesitación, de vacilación. Con lo cual no habría que esperar un fundamento sustantivo y estable donde se redimiría la esencia del mundo, antes bien, habría que ver ahí algo que funda sólo en la medida en que no puede fundar nada, en que permanece abierto, incompleto, no acabado. Un fundamento que vacila no fundamenta nada de manera permanente, sin embargo, no desaparece, pues ahora es esta vacilación, esta hesitación, esta incompletud. Es por esta razón que Heidegger cambia de terminología: para distinguir al ser como fundamento del ser como acontecimiento sustituye la expresión Sein por la de Seyn; con ella quiere dejar clara esta dimensión del ser en la cual éste es la condición de posibilidad de todo ente, pero al esenciarse en ellos se retira en beneficio de tal donación. Este dar lugar sin aparecer a la vista es propiamente el acontecimiento, el acaecer, ahí el ser permanece en la sombra y, sin embargo, pone todo en marcha, separándose de aquello a lo que da lugar, retirándose, desfondándose en el mismo momento que funda.

Pero aún más, si el Seyn funda a los entes en su retirada, al mismo tiempo él no puede fundarse, está desfondado. Esta falta de fundamento, este estar no-lleno es lo que abre el ámbito de la libertad, 
pues nada está decidido en el ámbito de lo mundano, de lo fáctico, de lo óntico, nada puede llenarse definitivamente pues lo que puede llenar está en sí mismo no lleno, por ende, se retira dejando sin llenar, dejándonos en este mundo fáctico abiertos a lo posible. Heidegger habla paradójicamente de 'exceso', es decir, el ser se sustrae a toda representación y medida, no puede llenarse precisamente porque está por encima de cualquier medida: exceso. "El exceso no es ningún mero demasiado cuantitativo sino el sustraerse a toda apreciación y medida. Pero en este sustraerse (ocultarse), el ser [Seyn] tiene su más cercana cercanía en el claro del ahí, en tanto acaece-apropiadoramente al serahî" (Heidegger, 201la: 205).

Lo interesante de este punto es darnos cuenta de que el ser (Seyn) ya no puede tomarse como fundamento, sino como acontecimiento, como este aparecer-desaparecer (ocultarse) de lo ontológico en lo óntico; por tanto, lo ontológico sólo puede acaecer en lo óntico, sólo se nos presenta en lo que ya no es, en el nivel de la facticidad. Sin duda tal idea resulta paradójica, pues nos habla de que el ser sólo aparece ahí donde ya no puede aparecer, en el ámbito de los entes; sin embargo, es sólo en este ámbito que podemos saber de él. En otros términos, aunque el ser debe pensarse por sí mismo y no confundirse con los entes, por otro lado su verdad está abrigada en los entes. Porque no podemos acceder directamente al nivel ontológico, es necesario pasar por lo óntico, por lo fáctico, por la historicidad; es desde ahí que el ser nos "hace señas", pero nunca se presenta tal cual, pues la brecha entre ambos niveles nunca se supera, pero tampoco se trata de una ruptura absoluta. En suma, el ser se esencia en lo óntico, en lo fáctico, en la historia, y es en ésta que el ser nos acaece: el ser como acontecimiento. "La historia, no la mundana sustitución de una desmoronada 'eternidad' [...], sino la historia como esenciarse de la verdad del ser (Seyn). [...] La inicial historicidad a partir del ser [Seyn] es lo que nos adviene" (Heidegger, 2011b: 39). Si bien el ser no nos es accesible de manera directa, es a través de la facticidad del hombre que se esencia y, al revés, en ese esenciarse del ser en el acontecimiento el hombre le muestra su pertenencia: "El ser [necesita] del hombre para esenciarse, y el hombre pertenece al ser [Seyn], para realizar su extrema determinación como ser ahí" (Heidegger, 2011a: 207). 
La estructura paradójica de la relación entre lo óntico y lo ontológico salta a la vista, pues el primero puede hacer aparecer al segundo sólo en la medida en que no lo puede hacer aparecer; es decir, lo óntico es a la vez condición de posibilidad y condición de imposibilidad para que lo ontológico se presente: lo ontológico se realiza sólo ahí donde no puede realizarse, en el ámbito fáctico-mundano. Se trata, así, de un fundamento que no puede fundarse a sí mismo ni puede fundamentar nada fuera de él de manera permanente. Con lo cual volvemos a dar con el tema de la libertad, pues un fundamento sin fondo, que no puede fundamentar cosa alguna, ni siquiera a sí mismo, nos deja en un mundo abierto a la contingencia, en medio de una extraordinaria libertad en la que aún es posible que por fin ocurra algo, para utilizar una expresión de Alain Badiou. Así, aunque siga existiendo la diferencia entre lo óntico y lo ontológico, y este último siga funcionando como fundamento, este fundamento que vacila y hesita no puede fundar más que la apertura a que lo posible ocurra, a la contingencia. De hecho, tendríamos que hablar de una contingencia (C) en el sentido fuerte, pues no se trata simplemente de que los entes no sean necesarios ( $\neg \mathrm{p}$ ) y no sean imposibles $[\neg(\neg \vartheta \mathrm{p})]$ — concepción débil de la contingencia-, sino de que es necesario ( $\square$ ) que no sean ni necesarios ni imposibles.

\begin{tabular}{|c|c|}
\hline Contingencia débil & Contingencia fuerte \\
\hline $\mathrm{Cp} \mathrm{p}^{-} \equiv \neg \square \mathrm{p} \& \neg(\neg \vee \mathrm{p})$ & $\mathrm{Cp}^{+} \equiv \square[\neg \square \mathrm{p} \& \neg(\neg \vee \mathrm{p})]$ \\
\hline
\end{tabular}

Es precisamente el carácter de abismo del fundamento al que apela Heidegger lo que permite fundar la libertad de lo óntico, es decir, la imposibilidad de fundarlo de manera permanente, una contingencia en la que necesariamente nada es necesario ni imposible. Así, este mundo fáctico-óntico en el que nos movemos sólo puede fundarse en algo que no puede fundarlo, por tanto, permanece abierto, libre, contingente. Esta idea nodal que encontramos en particular en Aportes a la filosofía —identificada desde Ser y tiempo como "diferencia ontológica" - es, sin duda, el argumento detrás de la diferencia entre lo político y la política, argumento caro al pensamiento posfundacional, 
pues, como ya habíamos adelantado, la urgencia de repensar la política - y en particular la idea de comunidad, ante el fin de comunismo real, la caída del muro de Berlín, el proclamado "fin de la historia" y la hegemonía planetaria de la democracia liberal- llevó a algunos pensadores a buscar un nuevo fundamento para la misma, mismo que encontraron no precisamente en una jerga político-sociológica, sino en una filosófico-ontológica. Ya señalamos lo paradójico que puede parecer este sendero, pues se podría esperar que recurrir a argumentos ontológicos sólo tendría como resultado una fundamentación fuerte de la política, pero siguiendo la senda heideggeriana sucedió exactamente lo contrario: apelando a este fundamento desfondado y vacilante, estos pensadores encontraron que la política - y con ella la comunidadsólo podría sostenerse en un fundamento político igualmente precario, hesitante, abismal.

\section{LAS TENSIONES ENTRE LO POLITITO Y LA POLITITA}

Si pensamos a la política como la dimensión óntica y a lo político como el nivel ontológico, tenemos un cuadro semejante al desplegado por la diferencia ontológica antes expuesta: se buscaba que la política real, concreta, fáctica, pudiera fundarse en un sustrato más esencial, más sustancial, que le diera su razón de ser, su orden y coherencia, ese fundamento estaría en una dimensión ontológica, en donde se encontraría la médula, la esencia de lo político. Por ejemplo, para Schmitt lo político sería ese fundamento que hace posible la vida política concreta, pero que no se confunde con ella; es decir, lo esencial de la vida política es el conflicto, el antagonismo es lo propiamente político, pero esta sustancia se rebaja y desvirtúa en la vida política concreta: los partidos, la representación democrática, las votaciones, todo está hecho para desvirtuar la esencia de la política, para rebajar lo político, en tanto de lo que ahí se trata es de eliminar el conflicto, la lucha, el enfrentamiento, la distinción amigo-enemigo. La política es, pues, una especie de epifenómeno de algo más fundamental, de algo que la hace posible, lo político, aunque éste desaparece en el ámbito ónticoconcreto de la política. 
Ante la crisis de la política que significó en muchos sentidos el siglo XX, el pensamiento posfundacional, al querer encontrar un nuevo fundamento para la política, encontró que aquél sólo podría dar cuenta de la complejidad de ésta renunciando a ser un fundamento absoluto. Estamos, así, ante una problemática paralela a la expuesta con la diferencia ontológica, pues si hay una esencia de la política, si ésta tiene algún fundamento, éste sólo puede encontrarse como fundamento desfondado, en retirada, vacilante. Para los autores llamados posfundacionales está claro que todo intento de fundar la política en un sustrato duro o sustancial llevó, como lo hizo evidente el siglo XX, a la pululación de regímenes totalitarios y fascistas. Sin embargo, renunciar sin más a todo fundamento no fue precisamente la mejor apuesta; los trabajos de Michel Foucault en torno al liberalismo y la gubernamentalidad pusieron sobre la mesa el hecho de que reducir la política a puro procedimiento, a pura gestión y administración, evitando cualquier forma de fundamentación — trátese de un ideal, un principio o un paradigma - nos ha hecho caer en una de las peores formas de control y violencia, en la que la vida, los cuerpos y los destinos de las personas se han convertido en meros números y estadísticas, en meros procedimientos para lograr metas administrativas y de gestión, lo que ciertamente Foucault identifica con la gubernamentalidad y biopolítica (2004). Gilles Deleuze no dejó de pronunciarse sobre el tema, para él lo característico de las sociedades liberales — llamadas por él "sociedades de control" - es el carácter suave a través del cual se administra la vida de las personas, una forma de ejercer el poder que ha renunciado en buena medida a la coerción, al encierro, a la disciplina, y ha encontrado que se gobierna mejor no bloqueando los flujos, sino montándose sobre ellos: flujos de dinero, de personas, de mercancías, de ideas, etcétera. "El hombre de las disciplinas era un productor discontinuo de energía, pero el hombre del control es más bien ondulatorio, puesto en órbita, sobre un haz continuo. Por todos lados el surf ha reemplazado los viejos deportes" (Deleuze, 1990: 244).

La renuncia del liberalismo a fundar la política en un sustrato ontológicamente fuerte, su capacidad de ser pura gestión y operatividad sin fundamento, no llevó precisamente a un mundo más libre ni dio lugar a una verdadera comunidad; todo lo contrario, la inmanencia 
individualista caracterizó finalmente tanto a la empresa comunista como a las democracias liberales, pero es sobre todo en esta última que la negativa a dar con un fundamento de la política no se tradujo en la construcción de una sociedad más libre y mucho menos en la construcción de una vida en común; más bien a la inversa, haber rechazado todo fundamento significó dejar de pensar la política, significó abandonar lo político no sólo como lugar de fundamentación, sino también como lugar de reflexión, de crítica y de resistencia. La renuncia a todo fundamento, la renuncia a lo político, no se tradujo en la solución de los problemas que la política, al menos en el siglo XX, evidenció con sus recurrentes crisis, fascismos, totalitarismos, comunismos y democracias liberales. Crisis que, en muchos sentidos, se hicieron patentes en la forma de una verdadera ausencia de comunidad. De hecho, la falta de un fundamento puede verse también como la ausencia de toda inclinación, de toda tendencia o vocación (clinamen ${ }^{2}$ para Jean-Luc Nancy) para estar en común. "Al final, no se hace un mundo con simples átomos. Hace falta un clinamen. Hace falta una pendiente o una inclinación de uno hacia otro, del uno por el otro o del uno al otro. La comunidad es al menos el clinamen del individuo" (Nancy, 2004: 17).

Lo que encontraron pensadores como Roberto Esposito, Alain Badiou, Jean-Luc Nancy, Claude Lefort, Giorgio Agamben, entre otros, es que para repensar a la política y a la comunidad no era posible ni volver al fundamentalismo radical, pero tampoco renunciar a todo fundamento, la solución transitó por derroteros de la ontología política que, retomando las ideas heideggerianas antes expuestas, apostó por

\footnotetext{
${ }^{2}$ En el vocabulario de la física epicuriana, los átomos se encuentran originariamente aislados, caen aisladamente de manera vertical, el clinamen es una desviación azarosa que permite que éstos se dirijan unos contra otros, chocando y conjuntándose en grupos mayores. Es en el libro segundo de De rerum natura de Lucrecio que queda mejor explicado este movimiento: "[...] cuando los cuerpos primeros son llevados de lo alto a lo bajo, todo derecho hacia el vacío, por su propio peso, en un momento indeterminado, en un lugar indeterminado, ello abandonan un poco la línea derecha; lo justo para que tú puedas hablar de un movimiento modificado. [...] Si ellos no declinaran, de arriba hacia abajo, como las gotas de lluvia, caerían a través de la profundidad del vacío; no habría colisión, ningún choque se produciría entre los elementos primeros; de esta manera la naturaleza no habría sido jamás creada" (Lucrecio, 2010: §216-224).
} 
dar con un fundamento; desfondado, vacilante, en retirada, abismal. A partir de tal perspectiva, la relación entre lo político (lo ontológico) y la política (lo óntico) se complica considerablemente, pues si bien entre ambos niveles existe una diferencia radical, ello no impide que se traslapen, que entre ambos exista un quiasmo, una verdadera zona de indiferenciación; aún más, la relación que despliegan no puede reducirse a un esquema vertical ni ascendente, como si la única dirección posible de tal relación sea de lo óntico hacia lo ontológico en busca de fundamento; antes bien, si algo se hace evidente en los autores citados es que no hay un fundamento último de la política, más bien dicho fundamento ontológico se ha disipado, ha dejado de ser un verdadero horizonte de inteligibilidad para la compleja realidad política, con lo cual la distancia entre lo óntico y lo ontológico se desdibuja, haciendo imposible basar de manera resolutiva la política en un fundamento último. Para estos teóricos, la política se funda en su contingencia, en su realidad óntica, en su aspecto político-social, con lo cual sólo se puede encontrar para ella una "fundación contingente", pero contingente en el sentido fuerte, lo cual no es igual a la ausencia de todo fundamento, pues se trata de un fundar parcial, vacilante.

La zona de indiferenciación entre lo óntico y lo ontológico se hace patente en tanto el primero muestra su fundamento como ausencia, como abismo, es decir, el fundamento se muestra sólo retirándose. Es por esta razón que los autores que aquí nos convocan utilizan un discurso en el que resulta difícil distinguir tajantemente cuándo se están refiriendo a la política y cuándo a lo político, pues precisamente esa falta de fundamento abre un quiasmo con consecuencias discursivas que se hacen patentes en el hecho de que el ser, es decir, el fundamento, sólo puede expresarse en términos contingentes, de acontecimiento.

Si bien estas nociones se localizan dentro del discurso, la retirada misma sólo puede experimentarse como un acontecimiento que perturba todo discurso fundacional. La ausencia misma de fundamento aparece o se 'materializa' únicamente bajo la forma, o a través de un acontecimiento que podría designarse, de acuerdo a Nancy, como libertad, compartir o ser-en-común. Sin embargo, en la obra de 
Nancy hay una constante lucha por interrogar desde dentro del discurso lo que sólo puede pensarse como la experiencia de un acontecimiento (Marchart, 2009: 108).

Nos parece que de manera semejante a Nancy, los autores que aquí nos convocan comparten este uso peculiar del discurso, uso que muestra una evidente tensión entre el querer dar cuenta de categorías fundacionales y ontológicas, y encontrar que ello sólo es posible a través de elementos que remiten a la realidad política concreta, óntica y contingente. En el caso de la comunidad, es difícil separar de manera tajante el nivel óntico y el nivel ontológico, pues ambos se comprenden y se contienen. Fórmula que no deja de ser en sí misma paradójica, pues la política sólo puede encontrar su máximo de certeza, su fundamento, en la contingencia.

Todo este panorama nos lleva, finalmente, a reconocer que desde el punto de vista posfundacional la única relación posible entre lo político y la política es una relación tensa, paradójica, pero es solamente salvaguardando tal tensión que puede esperarse conjurar tanto el esquema totalitarista en el cual lo político engulle la política (buscando darle un fundamento último y absoluto), como el esquema liberal que, abjurando de todo fundamento, hace de la política un mero procedimiento de gestión y administración de los cuerpos y la vida. Algunos autores han pensado esta dicotomía en términos de hiperpolitización y despolitización; la primera refiere precisamente a la hegemonía total de lo político (totalitarismo, fascismo, comunismo), mientras que la segunda refiere a la carencia de todo fundamento (liberalismo). La segunda alternativa, que es sin duda la más problemática, ha sido la más pensada por los autores citados, sobre todo porque pareciera que renunciando a todo fundamento se evitarían los mayores horrores que el totalitarismo, el fascismo y el mismo comunismo hicieron posibles, pero la cuestión no es tan sencilla.

La paradoja que vincula despolitización e hiperpolitización se muestra con claridad al considerar a la propia despolitización como el resultado triunfante de un gesto político radical: precisamente en el que lograría ocultar el 
carácter no natural de nuestro orden social apareciendo éste ante nuestros ojos naturalizado como obvio y, por tanto, como no político, como mera objetividad no cuestionada, ni cuestionable. ¿No es esta la máxima violencia (política), la que oculta sus propios orígenes violentos (políticos)? ¿No es, por tanto, la despolitización [...], el resultado de un conjunto de esfuerzos (políticos) destinados a aplacar las posibilidades de cuestionamiento y politización de lo dado, es decir, a contener la hiperpolitización latente de nuestro mundo? (Ema, 2007: 54).

El meollo de las sociedades liberales es que tratando de abjurar de todo fundamento no han logrado erradicar la violencia y el terror que caracterizó a los regímenes totalitarios; sin embargo, lo más violento ha sido ocultar tal fondo estridente haciéndonos creer que la política, como mera superficie, como mero procedimiento y gestión, es lo que es por su propia forma, por su propio proceder: es algo natural que no se debe a ningún fundamento, sino sólo a su actuar concreto. En suma, se trata de ver a una política sin tensiones, sin paradojas, sin ese fondo que la convierte en un círculo que nunca cierra -incompletud que le permite estar abierta a lo posible y a la crítica-; se trata pues de "la despolitización liberal-democrática que ha ocultado la dimensión de conflicto y negatividad inherente a toda relación social bajo la ilusión de la reconciliación universal" (Ema, 2007: 53). La apuesta liberal por una sociedad despolitizada, de una política que no requiere de ningún fundamento sino que se justifica en su propio proceder, es precisamente lo que ha hecho que esta forma de gobierno no pueda abjurar la violencia; al contrario, ha logrado potenciarla más; no obstante, lo que sí ha conseguido exitosamente es inhibir la crítica, pues al hacer aparecer a la política como obvia y natural, las posibilidades de cuestionarla y criticarla se reducen dramáticamente.

De ahí la necesidad de salvaguardar la tensión entre lo político y la política, pues ello significa tanto rechazar todo fundamento permanente y último, a la vez que negarse a carecer de todo fundamento; se trata, entonces, de pensar el fundamento como abismo, como retirada, como algo que sólo puede hacerse presente en aquello que no puede 
dar cuenta de él, es decir, en lo fáctico, en lo mundano. Pero de igual forma, la tensión entre ambos niveles es necesaria para evitar que la política lo engulla todo, para evitar que todo lo convierta en mero procedimiento y gestión y, con ello, hacernos creer que la política es sólo eso, su superficie, su hacer, sus procedimientos, por ende, que se trata de un círculo que cierra a la perfección. La necesidad de preservar la tensión entre lo político y la política implica entonces que la segunda sea una faena interminable, un círculo que nunca se cierra, pues es precisamente la falta de un fundamento estable lo que la deja abierta a lo posible.

Esta imposibilidad de encontrar fundamentos últimos es precisamente la condición misma de la política y supone una mayor oportunidad para una politización de las relaciones sociales al mostrar que no tenemos que ser o realizar ninguna esencia o sustancia, ningún destino histórico, espiritual o biológico. En realidad, si tuviéramos un destino, una sustancia, o un fundamento último que expresar, no habría política, sino reglas a seguir. Sería el fin mismo de la vida como posibilidad de creación y placer; y la victoria de la serie, la repetición y la gestión de lo mismo (Ema, 2007: 54).

La cuestión es ahora preguntarnos qué nos pueden indicar tales ideas a la hora de pensar a la comunidad. Ya habíamos adelantado varias cuestiones. La principal es que para el pensamiento posfundacional es necesario volver a pensar el estatus de la comunidad, pero sin buscar una esencia o fundamento estable que la defina; antes bien, habría que pensarla asumiendo su carácter paradójico, como un proceso interminable, como algo que sólo puede fundarse en su propia contingencia. Sólo una comunidad que puede hacerse cargo de su carácter paradójico, es decir, realizable en la medida en que no se realiza, puede concebirse como una verdadera comunidad. 
CODA: LA COMUNIDAD APORÉTICA

Cerramos el presente trabajo retomando algunas ideas que tratan de dibujar la forma de una comunidad que trataría de hacerse cargo de sus contradicciones, que no sólo puede sobrevivir, sino que debería su condición de posibilidad a que profundiza la tensión entre lo ontológico (lo político) y lo óntico (la política).

Las propuestas de los llamados pensadores posfundacionales nos invitan, entre otras cosas, a repensar la política renunciando a todo fundamento estable, pero también evitando renunciar a todo fundamento; más bien se trataría de pensarlo a la manera heideggeriana: un fundamento que se expresa como acontecimiento, que se realiza ahí donde no puede presentarse, que se oculta y vacila en el mismo acto del fundar. Sin un fundamento estable, ni la política ni la comunidad pueden aparecer como círculos que cierran perfectamente, como espacios transparentes donde sin conflicto ni hostilidad, todos perteneceríamos sin resto, ${ }^{3}$ en total igualdad y homogeneidad. Sin duda ha sido esta manera mítica e idealista de concebir a la comunidad lo que la ha arrojado a sus peores crisis; frente a ello, los autores citados apuestan por concebirla como algo que es realizable sólo en la medida en que asume su incompletud, sus tensiones, sus paradojas, su carácter de círculo que nunca cierra. Es decir, una comunidad que no renuncia a la tensión existente entre lo óntico y lo ontológico, pues si existe un fundamento ontológico que pueda guiar y darle forma, éste sólo puede realizarse en la medida en que no puede aparecer tal cual en el nivel fáctico, mundano, concreto. Si uno de los principios en los que se ha forjado nuestra idea de comunidad es el de la propiedad - pues en ella, se supone, encontramos lo que nos es más propio-, se trata entonces, desde la lógica posfundacional, de que las comunidades concretas - si hemos de evitar su fracaso- expresen lo propio en la más radical impropiedad.

\footnotetext{
3 Tomamos aquí la palabra "resto" en el sentido derrideano, no solamente como aquello que sobra, sino sobre todo como el exceso, lo supernumerario que impide la totalización, que los círculos cierren perfectamente, que las partes del sistema embonen a la perfección. Véase Derrida (1981).
} 
Esposito es quien mejor da cuenta de esta condición ciertamente paradójica. En su obra encontramos una aguda crítica a la concepción tradicional de comunidad por estar precisamente atada a ciertos valores y presupuestos que creemos evidentes e inamovibles (fundamentales). En concreto, solemos ligar a la comunidad con las ideas de identidad, propiedad y pertenencia.

El resultado es que se remite la comunidad a la figura del propium: se trata de comunicar cuanto es común o propio, de modo que la continuidad queda definida por las mismas propiedades - territoriales, étnicas, lingüísticas- de sus miembros. Estos tienen en común su carácter propio y son propietarios de aquello que es común (Esposito, 2009: 15).

Sin embargo, para Esposito los problemas comienzan cuando nos percatamos de que al querer encontrar lo propio en los demás terminamos perdiendo toda propiedad, que cuando queremos identificarnos con los demás perdemos toda identidad. Pero estas paradojas, lejos de ser aberraciones del estar en común son lo que lo constituye. Es decir, vivir en comunidad es asumir que no hay propiedad que podamos tener en común, pues si hay algo en común es aquello que no es propio, que es de todos, que es anónimo: "¿Qué otra cosa es lo 〈común〉 sino lo impropio, aquello que no es propio de ninguno, sino precisamente general, anónimo, indeterminado? Sin determinaciones de esencia, de raza, de sexo: pura existencia expuesta a la ausencia de sentido, de raíz, de destino" (Esposito, 2009: 92).

Así, tal parece que la comunidad es, a la vez, un encuentro y un desencuentro, el lugar donde nos encontramos y nos diferimos al mismo tiempo, un hallarse en casa y un estar lejos de ella. Es probable que si queremos entender qué es una comunidad, con todos sus vericuetos y contradicciones, tengamos que reconocer que para ello es necesario no superar tales contrasentidos, sino precisamente hacernos cargo de ellos. En otros términos, superar el mito de la comunidad y darle un contenido concreto, cercano a nuestra experiencia más mundana, significa aceptar que ella es realizable sólo en las paradojas que conlleva, es decir, en el 
hecho de que no es realizable. Pero no habría que ver en este carácter irrealizable un defecto, todo lo contrario. Es gracias a que nunca es posible hallar la identidad absoluta, a que nunca podremos sentirnos plenamente pertenecientes a un grupo, a que nunca encontraremos lo propio en los demás, es gracias a todo ello que la comunidad es posible y puede ser un espacio de libertad.

Bien podríamos decir que una comunidad que no cierra, que no se acaba, que no se completa, que no se fundamenta de manera segura ni permanente en ningún plano ontológico -una comunidad que viene, que nunca deja de venir, tomando los términos agambianos- es una que asume su carácter ético. Es sólo asumiendo que la comunidad se realiza no realizándose —es decir, no consolidándose en una pertenencia, en una identidad y en una propiedad permanentes - que la posibilidad de una vida humana, ética y libre se perfila como posible.

El hecho que debe constituir el punto de partida de cualquier discurso en ética es que no hay esencia, ni vocación histórica o espiritual, ni destino biológico que los hombres estén obligados a realizar. Esta es la única razón de que algo como la ética exista, ya que está claro que si los seres humanos fueran o tuvieran esta u otra sustancia, este u otro destino, no habría posibilidad de alguna experiencia ética —sólo habría tareas por hacer- (Agamben, 2007: 43).

Mantener la tensión entre lo óntico y lo ontológico significa negarse a toda fundamentación última, pero también a toda carencia de fundamento; significa hacerse cargo del carácter paradójico de la comunidad, a la vez que afirmar su carácter de contingencia necesaria: en ella necesariamente nada es necesario y nada es imposible. En conclusión, si queremos soslayar los fracasos recurrentes de la comunidad, de los que el siglo XX y el presente han sido testigos —algo que se ha reflejado claramente en la pululación de sectarismos, racismos, fascismos, totalitarismos, individualismos, discriminación, guettización, etcétera- habremos entonces de cultivar su carácter ético — sin esencia, sin vocación, es decir, su carácter expuesto-; habremos de evitar el mal, en tanto — siguiendo 
a Alain Badiou- el mal sería el intento de fundar lo infundable. Y evitar el mal implicaría, por lo mismo, no poder nombrar la comunidad, negarse a verla reducida a un mote, una medida, un símbolo, una pertenencia, una identidad: "la comunidad, lo colectivo, son los innombrables de la política: toda tentativa de nombrar 'políticamente' una comunidad induce un Mal desastroso" (Badiou, 2004: 123).

\section{FuENTES CONSULTADAS}

Agamben, G. (2007), The Coming Community, Minneapolis: University of Minnesota Press.

Aristóteles (1994), Metafísica, Madrid: Gredos.

Badiou, A. (2004), La ética, México: Herder. (1999), El ser y el acontecimiento, Buenos Aires: Manantial.

Blanchot, M. (1983), La Communauté Inavouable, París: Les éditions de minuit.

Deleuze, G. (1990), Pourparlers, París: Minuit.

Derrida, J, (1981), Espolones. Los estilos de Nietzsche, Valencia: Pretextos. Ema López, J.E. (2007), "Lo político, la política y el acontecimiento", en Foro interno. Anuario de Teoría Política, núm. 7, Madrid: Universidad Complutense. p. 51-76.

Esposito, R. (2009), Comunidad, inmunidad y biopolitica, Madrid: Herder. (2003), Communitas. Origen y destino de la comunidad, Buenos Aires: Amorrortu.

Foucault, M. (2004), Naissance de la Biopolitique, París: Seuil-Gallimard. Fukuyama, F. (1992), El fin de la historia y el último hombre, México: Planeta.

Heidegger, M. (2011a), Aportes a la filosofía. Acerca del evento, Buenos Aires: Biblos.

(2011b), La historia del ser, Buenos Aires: El hilo de Ariadna. (2003), Ser y tiempo, Madrid: Trotta.

Kishik, D. (2012), The Power of Life. Agamben and the Coming Politics, California: Stanford University Press.

Lucrecio (2010), "La Nature des choses", en Daniel Delattre y Jachie Pigeaud (dir.), Les Epicuriens, París: La Pléiade. p. 271-531. 
MARChART, O. (2009), El pensamiento político posfundacional. La diferencia política en Nancy, Lefort, Badiou y Laclau, Buenos Aires: FCE.

Nancy, J. (2004), La Communauté Désœuvrée, París: Christian Burgois. (2001), La Communauté Affrontée, París: Galilée.

Sorensen, R. (2007), Breve historia de la paradoja, Barcelona: Tusquets.

Villarmea, S. (2001), "Paradojas, normatividad y praxis", en Revista Tales, núm. 4, Madrid: Universidad Complutense. p. 11-31.

Fecha de recepción: 12 de julio de 2013 Fecha de aceptación: 14 de enero de 2014 